\title{
Laminine et cancer
}

\section{Les nouvelles de ce numéro ont été préparées par: Jean-Claude Dreyfus Jean-Pierre Grünfeld} Axel Kahn
Connue depuis 1979 [1], la laminine est une glycoprotéine spécifique des membranes basales cellulaires. C'est une protéine de grande taille (environ $1000 \mathrm{kDa}$ ), formée de trois chaînes: A de $400 \mathrm{kDa}, \mathrm{BI}$ de $230 \mathrm{kDa}$ et $\mathrm{B} 2$ de $220 \mathrm{kDa}$, l'ensemble revêtant une forme en croix visible au microscope électronique [2]. Elle se fixe sur les cellules par un récepteur spécifique de $67 \mathrm{kDa}$. Ses activités biologiques sont multiples; elles concernent l'attachement et la différenciation de cellules épithéliales et la croissance de différentes cellules dont les neurites. Un intérêt particulier se porte sur les relations de la laminine et du cancer. Les cellules malignes ont plus de laminine à leur surface que les cellules normales et sont capables d'en lier davantage; on a donc cherché à explorer le mécanisme de cette fixation et à en contrecarrer les effets.

La dissection de la molécule de laminine devait permettre de définir les domaines qui sont le support des diverses proriétés. C'est ainsi que la capacité de promouvoir la croissance des cellules nerveuses a pu être localisée à une des extrémités du bras long de la croix [3]. Le clonage des chaînes devrait assurer des progrès importants dans cette direction. Une percée a été réalisée par un groupe du NIH $[4,5]$, qui a cloné le gène de la chaîne BI. Cette chaîne compte 1786 acides aminés répartis en sept domaines structuraux. Des peptides correspondant à chacun de ces domaines ont été préparés. Une séquence de neuf acides aminés, dite peptide 11 , a révélé des propriétés frappantes : étalée sur un support de plastique, elle stimulait l'attachement des cellules, et inhibait par compétition la fixation de cellules à la laminine. L'observation la plus importante est que, in vivo comme in vitro, le nonapeptide, et même son pentapeptide terminal, YIGSR (tyr-ile-glyser-arg), est capable de s'opposer à une invasion par des cellules tumorales. In vivo, ces peptides empêchent des cellules de mélanome injectées à des souris de coloniser le poumon. In vitro, ils préviennent la fixation de ces mêmes cellules dans le test dit d'invasion in vitro, qui met en jeu une matrice de membranes basales reconstituée et qui présente une bonne corrélation avec le pouvoir métastatique. Les auteurs concluent [5] que cette séquence peut empêcher la production de métastases expérimentales.

La séquence YIGSR est spécifique de la laminine et diffère totalement de la séquence d'adhésion RGDS, présente dans la fibronectine et d'autres protéines d'adhésion $\left(\mathrm{m} / \mathrm{s} n^{\circ} 6\right.$, vol. $2, p .337$ et $n^{\circ} 6, v o l .3$, p. 316). Rappelons toutefois que la séquence RGDS s'est montrée, elle aussi, capable d'inhiber des métastases de cellules de mélanome chez la souris $\left(m / s n^{\circ} 10\right.$, vol. $\left.2, p .586\right)$.

J.-C. D.

1. Timpl R, Rohde H, Robey GP, et al. Laminin-a glycoprotein from basement membrane.
J Biol Chem $1979 ; 254: 9933-7$.
2. Engel J, Odermatt E, Engel A, et al. Shapes, domain organizations and flexibility of laminin
and fibronectin, two multifunctional proteins of the extracellular matrix. J Mol Biol 1981 ;
$150: 97-120$.
3. Edgar D, Timpl R, Thoenen H. The heparin binding domain of laminin is responsible for
its effects on neurite outgrowth and neuronal survival. EMBO J $1984 ; 3: 1463-8$.
4. Graf J, Iwamoto Y, Sasaki M, et al. Identification of an amino acid sequence in laminin
mediating cell attachment, chemotaxis, and receptor binding. Cell $1987 ; 48: 989-96$.
5. Iwamoto Y, Robey FA, Graf J, et al. YIGSR, a synthetic laminin pentapeptide, inhibits
experimental metastasis formation. Science $1987 ; 238: 1132-4$.

$m / s n^{\circ} 2$ vol. 4, février 88 